\title{
Micronutrient fortification of plants through plant breeding: can it improve nutrition in man at low cost?
}

\author{
Howarth E. Bouis \\ International Food Policy Research Institute, 2033 K St NW, Washington DC 20006, USA
}

\begin{abstract}
Can commonly-eaten food staple crops be developed that fortify their seeds with essential minerals and vitamins? Can farmers be induced to grow such varieties? If so, would this result in a marked improvement in human nutrition at a lower cost than existing nutrition interventions? An interdisciplinary international effort is underway to breed for mineral- and vitamin-dense varieties of rice, wheat, maize, beans and cassava for release to farmers in developing countries. The biofortification strategy seeks to take advantage of the consistent daily consumption of large amounts of food staples by all family members, including women and children as they are most at risk for micronutrient malnutrition. As a consequence of the predominance of food staples in the diets of the poor, this strategy implicitly targets low-income households. After the one-time investment is made to develop seeds that fortify themselves, recurrent costs are low and germplasm may be shared internationally. It is this multiplier aspect of plant breeding across time and distance that makes it so cost-effective. Once in place, the biofortified crop system is highly sustainable. Nutritionally-improved varieties will continue to be grown and consumed year after year, even if government attention and international funding for micronutrient issues fades. Biofortification provides a truly feasible means of reaching malnourished populations in relatively remote rural areas, delivering naturally-fortified foods to population groups with limited access to commercially-marketed fortified foods that are more readily available in urban areas. Biofortification and commercial fortification are, therefore, highly complementary. Breeding for higher trace mineral density in seeds will not incur a yield penalty. Mineral-packed seeds sell themselves to farmers because, as recent research has shown, these trace minerals are essential in helping plants resist disease and other environmental stresses. More seedlings survive and initial growth is more rapid. Ultimately, yields are higher, particularly in trace mineral-'deficient' soils in arid regions.
\end{abstract}

Biofortification: Plant breeding strategy: Human micronutrient status: Biofortification $v$. commercial fortification

Taken together, mineral and vitamin deficiencies affect a greater number of the world's population than does proteinenergy malnutrition. As trace minerals are important not only for human nutrition, but also for plant nutrition, plant breeding holds great promise for making a major, low-cost and sustainable contribution to reducing micronutrient, particularly mineral, deficiencies in man, and may have important spin-off effects for increasing farm productivity in developing countries in a way that is environmentally beneficial (Graham \& Welch, 1996; Graham et al. 2001).

An underlying cause and fundamental constraint to the solution of the micronutrient problem is that non-staple foods, particularly animal products, tend to be the foods richest in bioavailable micronutrients, which the poor in many developing countries desire to eat, but cannot afford. Their diets consist mostly of staple foods, primarily cereals; in fact, per capita direct consumption of staple foods in the aggregate varies little by income level. For the poor, these staple foods already are primary sources of what micronutrients they are able to consume, particularly minerals.

The plant-breeding strategy seeks to take advantage of this existing human consumption behaviour by developing staple food crops that, in some sense, fortify themselves. Staple crop genotypes are bred that load high amounts of minerals and vitamins into their seeds, a strategy referred to in the present paper as 'biofortification'. 
Biofortification has several complementary advantages. No behavioural change on the part of consumers is required. Indeed, the strategy seeks to take advantage of the consistent daily consumption of large amounts of food staples by all family members. Nevertheless, any intervention to improve micronutrient status targets women and children because of their elevated needs for minerals and vitamins for reproduction and growth (for example, see Perry et al. 1995).

Biofortification provides a truly feasible means of reaching malnourished populations in relatively remote rural areas, delivering naturally-fortified foods to population groups with limited access to commercially-marketed fortified foods that are more readily available in urban areas. Biofortification and commercial fortification are, therefore, highly complementary.

Mineral-packed seeds will sell themselves to farmers because, as relatively recent research has shown, these trace minerals are essential in helping plants resist disease. More seedlings survive and initial growth is more rapid. Ultimately, yields are higher, particularly in trace mineral'deficient' soils in arid regions. After the one-time investment is made to develop seeds that fortify themselves, there are low recurrent costs, which for supplementation and fortification remain constant year after year.

\section{Micronutrient malnutrition: extent and underlying cause}

Billions in the populations of developing countries suffer from micronutrient malnutrition. Even mild levels of micronutrient malnutrition may damage cognitive development, lower disease resistance in children and reduce the likelihood that mothers survive childbirth. The costs of these deficiencies in terms of lives lost and poor quality of life are staggering (Table 1).

More than two billion of the world's population are Fe deficient (ACC/SCN, 2000; Stoltzfus, 2001). Fe-deficiency anaemia is by far the most common micronutrient deficiency in the world. Fe deficiency during childhood and adolescence impairs physical growth, mental development and learning capacity. In adults Fe-deficiency anaemia reduces the capacity to do physical labour. Fe deficiency increases the risk of women dying during delivery or in the postpartum period.

$\mathrm{Zn}$ deficiencies have equally serious consequences for health. For example, meta-analyses of recent randomised controlled trials show that $\mathrm{Zn}$ supplementation can reduce morbidity from a number of common childhood infections, especially diarrhoea, pneumonia and, possibly, malaria by one-third (Black, 1998; Bhutta et al. 1999, 2000; Roy et al. 1999; Shankar et al. 2000). In addition, Zn deficiency is an important cause of stunting (Roy et al. 1999; Brown \& Wuehler, 2000; Umeta et al. 2000). Billions of individuals are also at risk for Zn deficiency (Brown \& Wuehler, 2000).

Globally, approximately three million preschool children have visible eye damage as a result of vitamin A deficiency. Annually, an estimated 250 000-500 000 preschool children go blind from this deficiency and about two-thirds of these children die within months of going blind. Even more importantly, the last two decades have brought an awareness that vitamin $\mathrm{A}$ is essential for immune function. Estimates of the prevalence of subclinical vitamin A deficiency range between 100 and 250 million for preschool children. Individuals with subclinical vitamin A deficiency more often experience anaemia, impaired linear growth (Villamor \& Fawzi, 2000) and morbidity from common childhood infections, such as respiratory and diarrhoeal diseases (Sommer \& West, 1996), measles (West, 2000) and malaria (Shankar et al. 1999). Most importantly, a number of randomised controlled trials in developing countries have shown that administration of vitamin A capsules to infants and preschool children helps reduce mortality rates from all causes by $23 \%$ (Beaton et al. 1993; Sommer \& West, 1996) and that administration of capsules with vitamin A or $\beta$-carotene to women of childbearing age can reduce maternal mortality related to pregnancy by 40 and $49 \%$ respectively.

The primary underlying cause of micronutrient malnutrition is poor-quality diets, characterised by high intakes of food staples, but low consumption of animal and fish products, fruits, lentils and vegetables, which are rich sources of bioavailable minerals and vitamins. As such, most of the population groups who are malnourished are those who cannot afford to purchase high-quality micronutrient-rich foods or who cannot obtain these foods from their own production (for an example from Bangladesh, see Fig. 1).

What is perhaps most alarming, however, is the upward trend in non-staple food prices, shown in Fig. 2. Cereal prices have fallen by $40 \%$ since the early 1970 s. The Green Revolution can rightly take credit for its crucial contribution to this tremendous achievement. Falling cereal prices have not only led to increased food security in terms of energy, but also allowed greater purchases of non-staples by freeing up cash. Unfortunately, however, the rate of production of non-staple foods (e.g. fruits, vegetables, lentils) has not kept pace with demand (Fig. 3), so that these micronutrient-rich food sources have become increasingly expensive for the poor.

Table 1. Extent and consequences of micronutrient malnutrition (ACC/SCN, 2000)

\begin{tabular}{|c|c|c|c|}
\hline Deficiency & Prevalence in developing countries & Groups most affected & Consequences \\
\hline $\mathrm{Fe}$ & 2 billion of the population & $\begin{array}{l}\text { All, but especially women and } \\
\text { children }\end{array}$ & $\begin{array}{l}\text { Reduced cognitive ability, childbirth complications, } \\
\text { reduced physical capacity and productivity }\end{array}$ \\
\hline Vitamin A & 250 million children & Children and pregnant women & Increased child and maternal mortality, blindness \\
\hline $\mathrm{Zn}$ & May be as widespread as Fe deficiency & Women and children & $\begin{array}{l}\text { Illness from infectious diseases, poor child growth, } \\
\text { pregnancy and childbirth complications, } \\
\text { reduced birth weight }\end{array}$ \\
\hline
\end{tabular}


(a)

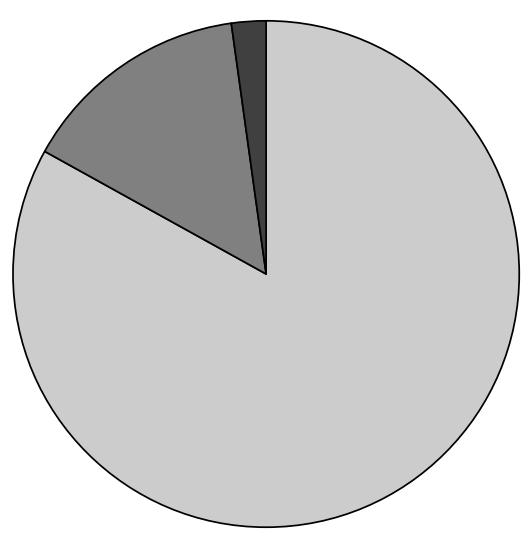

(b)

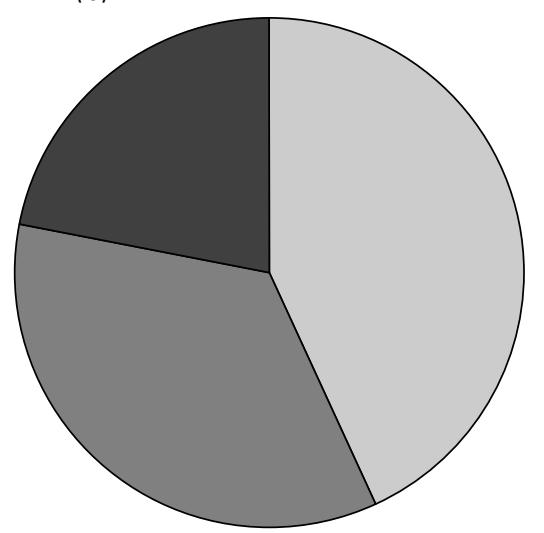

Fig. 1. Shares of energy intake (a) and food budget (b) for rural Bangladesh. The data shown are typical of diets and food expenditures for those who suffer from micronutrient malnutrition. ( $\square$ ), Staple foods (in this example, overwhelmingly rice) account for $80 \%$ total per capita energy intakes. (프), Animal and fish products are dense sources of bioavailable micronutrients that the poor wish to eat but cannot afford in large quantities. They account for $25 \%$ of the total food expenditures but only $3 \%$ of the total energy intakes. ( $\square$ ), Nonstaple plant foods such as fruits, vegetables, and lentils are also rich sources of vitamins and minerals. Together, non-staple plant foods and animal and fish products account for only $20 \%$ of the total energy intakes but $60 \%$ of the total food expenditures. (From Bouis et al. 1998.)

\section{Can a breeding strategy work?}

A strategy of breeding plants that enrich themselves will be successful only if farmers are willing to adopt such varieties, if the edible parts of these varieties are palatable and acceptable to consumers and if the micronutrients incorporated can be absorbed by the human body. In examining the feasibility of a plant-breeding strategy, it was imperative to address five core questions.

\section{Is it scientifically feasible to breed for staple food varieties whose seeds are micronutrient-dense?}

At least three cases of agricultural research projects in developed countries have successfully manipulated the

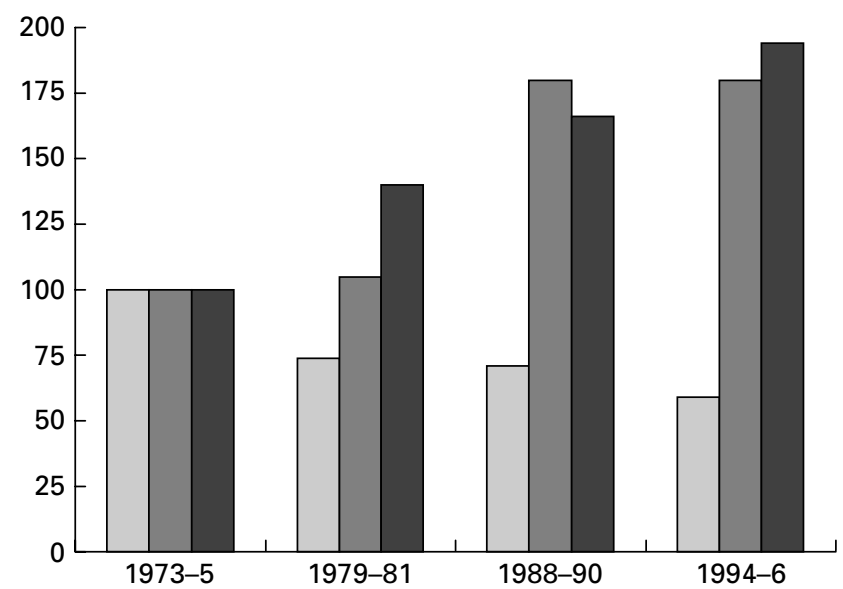

Fig. 2. Indices of inflation-adjusted prices for Bangladesh (where the $1973-5$ is taken as 100$)$. (品), staple; $(\square)$, non-staple plant; ( $\equiv)$, animal and fish. (From Bouis et al. 1998.)

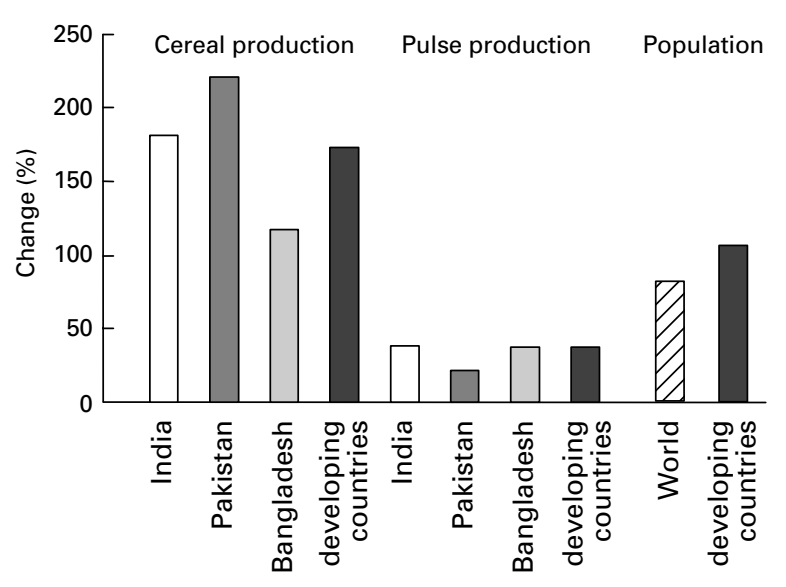

Fig. 3. Changes (\%) in cereal and pulse production and in population between 1965 and 1999. (From Food and Agriculture Organization, 1999.)

efficiency of mineral uptake of plants and the mineral content of plant seeds, all of which have been commercially successful. Zn-dense wheat varieties have been developed at the Waite Agricultural Research Institute of the University of Adelaide (Adelaide, Victoria, Australia) and are already being grown on a commercial basis in Australia (Rengel \& Graham, 1995a,b). In the USA an Fe-efficient soyabean has been developed to overcome problems of Fe-'deficient' soils, and $\mathrm{Cd}$ levels in durum wheat have been reduced through plant breeding in order to meet quality standards in countries importing US wheat.

The Australian wheat strategy was motivated by previous more basic scientific research at the Waite Agricultural Research Institute involving the trace minerals $\mathrm{Mn}$ and $\mathrm{Cu}$. Previous research suggested that genetic variation in the uptake and grain content of $\mathrm{Mn}, \mathrm{Cu}$ and other microelements was associated with tolerance to low availability of the elements in the soil. 


\section{What effect will breeding for micronutrient-dense seeds have} on plant yields? Will farmers adopt such varieties?

Good nutritional balance is as important to disease resistance and stress tolerance in plants as it is in man. Micronutrient deficiency in plants greatly increases their susceptibility to diseases, especially fungal root diseases of the major food crops. Efficiency in the uptake of mineral micronutrients from the soil is associated with disease resistance in plants. Breeding for micronutrient efficiency can confer resistance to root diseases that had previously been unattainable (Graham \& Rovira, 1984; Sparrow \& Graham, 1988; Thongbai et al. 1993).

Micronutrient-efficient varieties grow deeper roots in mineral-deficient soils and are better at tapping subsoil water and minerals. When topsoil dries, roots in the dry soil zone (which are the easiest to fertilise) are largely deactivated and the plant must rely on deeper roots for further nutrition. Roots of plant genotypes that are efficient in mobilising surrounding external minerals are not only more disease resistant, but are better able to penetrate deficient subsoils and so make use of the moisture and minerals contained in subsoils. These characteristics reduce the need for fertilisers and irrigation. Plants with deeper root systems are more drought resistant.

Micronutrient-dense seeds are associated with greater seedling vigour that, in turn, is associated with higher plant yield (Welch, 1986, 1995, 1999; Graham, 1991; Marschner, 1995; Graham \& Welch, 1996; Yang \& Römheld, 1999).

A substantial percentage of the soils in which staple foods are grown are 'deficient' in these trace minerals, which has kept crop yields low. In general, these soils, in fact, contain high amounts of trace minerals, enough for hundreds or thousands of crops. However, because of chemical binding to other compounds, these trace minerals are 'unavailable' to staple crop varieties presently used. Depletion of soils of trace minerals may never occur, because of various inadvertent additions, such as windblown dust (Graham, 1978; Sillanpaa, 1990; Graham \& Welch, 1996).

Thus, the traits of efficient uptake of trace minerals from the soil and of loading of those trace minerals into the seed are compatible with breeding for high yields. Based on a profit motive, farmers can be expected to adopt genotypes with trace mineral-dense seeds.

\section{Will breeding for micronutrient-dense seeds change the processing or consumer characteristics of staple foods?}

Mineral micronutrients make up a very small proportion of the physical mass of a seed, $5-10 \mathrm{mg} / \mathrm{kg}$ in milled rice. Dense bean seeds may contain as much as $100 \mathrm{mg} / \mathrm{kg}$. Whether such small amounts will alter the appearance, taste, texture or cooking quality of foods will need to be investigated. If increased densities of $\mathrm{Fe}$ and $\mathrm{Zn}$ are not noticeable to consumers, the dissemination strategy for trace minerals, therefore, could rely on existing producer and consumer behaviour. Analogous to the addition of fluoride to drinking water in some developed countries, successful implementation would not require that farmers and consumers know that they are producing and eating more nutritious varieties, although this information would be publicly advertised and publicly available.
Increasing the seed content of $\beta$-carotene, which is associated with an orange or yellow colour, will alter its colour, which might well reduce consumer preference. However, nutrition education could turn this obstacle to an advantage, as consumers could be taught that deepness of colour is visually representative of a nutrient-dense product.

Will micronutrient intakes be increased to a marked extent? To what extent will the extra micronutrients in staple foods consumed be bioavailable?

For the poor, these staple foods are already primary sources of what micronutrients they are able to consume, particularly minerals. This situation is demonstrated by food intake data shown in Table 2 for survey populations in Bangladesh and the Philippines (Bouis \& Haddad, 1990; Bouis \& Novenario-Reese, 1997). Average incomes in these households range from US $\$ 45$ per capita per year in the poorest $20 \%$ of the households surveyed to US $\$ 250$ in the richest $20 \%$ of the households surveyed. Thus, they are typical of the middle to lower end of the income distribution in rural areas of these countries.

Not only are food staples poor (non-dense) sources of trace minerals, but anti-nutrient (e.g. phytate) levels are high, which reduces the bioavailability of overall intakes of trace minerals. Nevertheless, for poor populations such as those represented in Table 2, food staple consumption so dominates diets (their low incomes preclude the consumption of desired levels of non-staple foods) that primary food staples provide in the range of $40-55 \%$ of the total $\mathrm{Fe}$ intakes for lower-income households.

If a single food staple provides $50 \%$ of the total $\mathrm{Fe}$ intakes for a poor population (e.g. for rice in Bangladesh), then a doubling of the $\mathrm{Fe}$ density in that food staple will result in a $50 \%$ increase in total $\mathrm{Fe}$ intakes, and a tripling of the $\mathrm{Fe}$ density will mean a doubling of total $\mathrm{Fe}$ intakes.

A key issue is the level of bioavailability of total $\mathrm{Fe}$ (or $\mathrm{Zn}$ ) intakes and whether the percentage bioavailability will remain constant as additional $\mathrm{Fe}$ and $\mathrm{Zn}$ is added to the diet through biofortification. In vitro and rat studies, for example, suggest that the percentage of the $\mathrm{Fe}$ (and $\mathrm{Zn}$ ) that is bioavailable remains relatively constant across cereal genotypes with high and low density (Welch et al. 2000; Glahn et al. 2002).

A second key issue is the range of genetic diversity in $\mathrm{Fe}$ (or $\mathrm{Zn}$ ) density that can be identified for use in breeding programmes, which will determine the maximum level to which trace mineral density can be increased. Germplasm screening under the Consultative Group on International Agricultural Research Micronutrients Project suggests that trace mineral content of cereals can be doubled as compared with commonly-eaten cereal genotypes (Graham et al. 1999). This improvement would increase the Fe intakes of the populations surveyed in Table 2 by about $50 \%$.

Fe-deficiency anaemia is widespread among adult women in developing countries. For the lower-income households in Table 2, Fe intakes for women range between 50 and $75 \%$ of the recommended daily allowances. Despite well-known difficulties associated with the determination of useful benchmarks for recommended daily allowances of $\mathrm{Fe}$, it would seem evident that a $50 \%$ increase in intakes of 
Table 2. Percentage contributions of staple foods to food expenditures per capita per week and to energy and iron intakes for survey populations in Bangladesh and the Philippines

\begin{tabular}{|c|c|c|c|c|c|c|}
\hline \multirow[b]{2}{*}{ Food group } & \multicolumn{2}{|c|}{$\begin{array}{c}\text { Poorest } 20 \% \text { of households } \\
\text { surveyed }\end{array}$} & \multicolumn{2}{|c|}{$\begin{array}{c}\text { Richest } 20 \% \text { of households } \\
\text { surveyed }\end{array}$} & \multicolumn{2}{|c|}{$\begin{array}{c}\text { Average for all households } \\
\text { surveyed }\end{array}$} \\
\hline & Bangladesh & Philippines & Bangladesh & Philippines & Bangladesh & Philippines \\
\hline \multicolumn{7}{|c|}{ Household food expenditure } \\
\hline Rice, wheat, maize & 69 & 45 & 54 & 24 & 62 & 33 \\
\hline Meat, fish & 9 & 28 & 19 & 39 & 14 & 32 \\
\hline Other foods & 22 & 27 & 27 & 37 & 24 & 35 \\
\hline Total & 100 & 100 & 100 & 100 & 100 & 100 \\
\hline \multicolumn{7}{|l|}{ Houshold energy intake } \\
\hline Rice, wheat, maize & 87 & 84 & 81 & 70 & 84 & 79 \\
\hline Meat, fish & 1 & 4 & 4 & 10 & 2 & 6 \\
\hline Other foods & 12 & 12 & 15 & 20 & 13 & 15 \\
\hline Total & 100 & 100 & 100 & 100 & 100 & 100 \\
\hline \multicolumn{7}{|l|}{ Household Fe intake } \\
\hline Rice, wheat, maize & 55 & 43 & 43 & 30 & 51 & 36 \\
\hline Meat, fish & 3 & 18 & 6 & 36 & 5 & 25 \\
\hline Other foods & 42 & 40 & 52 & 34 & 45 & 39 \\
\hline Total & 100 & 100 & 100 & 100 & 100 & 100 \\
\hline
\end{tabular}

bioavailable Fe would be of considerable benefit to anaemic women with such low Fe intakes. Nevertheless, studies in human subjects still need to be undertaken in order to measure the effects of increased Fe (or $\mathrm{Zn}$ ) density in food staples on $\mathrm{Fe}$ (or $\mathrm{Zn}$ ) status and consequent improvements in health and productivity.

Similar arguments apply to those staples in which pro-vitamin A content may be enriched by plant breeding (e.g. wheat, maize and cassava). Some differences apply, however, as compared with trace minerals. First, no agronomic advantages accrue to higher pro-vitamin A content, so that high density will need to be bred into varieties that are otherwise high-yielding. Second, the colour of the final food product may change so that consumers may need to be educated about the improved nutritional content. However, if education programmes are successful, the colour change becomes an advantage, in that it identifies those particular varieties of superior nutritional quality.

A breeding strategy of lowering the level of inhibiting substances (anti-nutrients, e.g. phytates) in the grain has often been suggested as a way of increasing the bioavailability of minerals already consumed (Wise, 1995; Raboy, 2002). Phytin is the primary storage form of $P$ in most mature seeds and grains and is an important compound required for early seed germination and seedling growth (Welch, 1986). Phytin plays an important role in determining mineral reserves of seeds and, thus, contributes to the viability and vigour of the seedling produced (Welch, 1993). Selecting for seed and grain crops with substantially lower phytin content could have an unacceptable effect on production, especially in regions of the world that have soils of low P status and/or poor micronutrient fertility (Graham \& Welch, 1996).

Such attempts to markedly lower the anti-nutrient content of seeds and grains require a major shift in seed or grain composition. As most of the anti-nutrients known to occur in seeds and grains are major organic constituents of these organs, they may play additional, but as yet unrecognised, beneficial roles in plant growth and human health. Thus, a breeding strategy of attempting to increase Fe bioavailability by reducing anti-nutrient content is not recommended (Graham \& Welch, 1996).

Certain amino acids (cysteine and lysine, but particularly methionine) enhance Fe and/or Zn bioavailability (Hallberg, 1981). These amino acids occur in many staple foods, but their concentrations are lower than those found in meat products. A modest increase in the concentrations of these amino acids in plant foods may have a positive effect on $\mathrm{Fe}$ and $\mathrm{Zn}$ bioavailability in man. Fe and $\mathrm{Zn}$ occur only in micromolar amounts in plant foods, so only micromolar increases in the amounts of these amino acids may be required to compensate for the negative effects of antinutrients on $\mathrm{Fe}$ and $\mathrm{Zn}$ bioavailability. These amino acids are essential nutrients for plants as well as for man, so relatively small increases of their concentrations in plant tissues should not have adverse consequences on plant growth. The optimal breeding strategy from the point of view of bioavailability may be to increase levels of promoter compounds (Graham \& Welch, 1996).

\section{Are there other lower-cost more easily sustainable strategies for reducing micronutrient malnutrition?}

A plant-breeding strategy, if successful, will not eliminate the need for supplementation, fortification, dietary diversification and disease reduction programmes in the future. Nevertheless, this strategy does hold promise for markedly reducing recurrent expenditures required for these higher-cost short-run programmes by substantially reducing the numbers of individuals requiring treatment.

The World Bank (1994) estimated that at the levels of micronutrient malnutrition existing in South Asia, $5 \%$ of the gross national product is lost each year due to deficiencies in the intakes of just three nutrients, Fe, vitamin A and I. For a 
hypothetical country with 50 million in the population burdened with this rate of malnutrition, deficiencies in these three nutrients could be eliminated through fortification programmes costing a total of $\$ 25 \times 10^{6}$ annually, or 50 cents per person per year. The monetary benefit of this $\$ 25 \times 10^{6}$ investment is quite high in terms of increased productivity, which is estimated to be $\$ 20$ per person per year, or a forty-fold return on an investment of 50 cents. These benchmark numbers will be used later as a basis of comparison with the benefits of a plant-breeding strategy.

While benefit:cost values are quite high, supplementation and fortification programmes must be sustained at more or less the same level of funding year after year in any given country. If investments are not sustained, benefits will of course disappear. Some back-of-the-envelope calculations may be made for the costs of supplementation and fortification in South Asia, which has a total population of approximately 1.25 billion.

Although the costs of vitamin A pills are low, an oftenquoted cost of vitamin A supplementation, which includes the costs of delivery, is US $\$ 0.50$ per person per year (25 cents per capsule; World Bank, 1994). If one in 12.5 of the population in South Asia were to receive supplements (100 million in total), this is a cost of $\$ 50 \times 10^{6}$ per year, or $\$ 500 \times 10^{6}$ over 10 years. An often-quoted cost of Fe fortification is US \$0.12 per person per year (World Bank, 1994). If a particular food vehicle to be fortified with $\mathrm{Fe}$ were to reach $33 \%$ of the total (but untargeted) population in South Asia (412 million), the total cost is again $\$ 50 \times 10^{6}$ annually, or $\$ 500 \times 10^{6}$ over 10 years. In absolute terms, these costs may seem to involve large amounts of money, but they are very worthwhile investments and are actually quite small percentages of the total economic activity of South Asia. Nevertheless, in contrast, investments in plantbreeding research and dissemination are far lower.

\section{Calculation of benefit:cost for biofortification}

The two fundamental reasons for expecting high payoffs to investments in breeding for $\mathrm{Fe}$ - and $\mathrm{Zn}$-dense seeds of food staple are: (1) fixed costs of research at a central location may accrue across countries and over time at low recurrent costs; (2) not only are there nutritional benefits, but agricultural productivity may also be increased. These factors may be demonstrated empirically with a simple benefit:cost calculation for India and Bangladesh, where the two major staples are rice and wheat (total population of 1.125 billion; $55 \times 10^{6}$ ha rice and $28 \times 10^{6}$ ha wheat harvested annually).

For any single staple crop, the estimated central fixed costs over 10 years of developing $\mathrm{Fe}$ - and $\mathrm{Zn}$-dense rice varieties are estimated to be $\$ 12.5 \times 10^{6}$. This estimate includes several costs not directly related to breeding, such as those of nutritional studies to establish efficacy and to demonstrate impact after adoption. Conservatively, it should be assumed that all these central fixed costs are charged to India and Bangladesh. It is further assumed that $\$ 2.5 \times 10^{6}$ per crop is spent on adaptive breeding specifically for growing conditions in India and Bangladesh, again over the same 10 -year period.

Various rates of adoption of nutritious varieties are assumed in the simulations, and extension costs are tied to the rates of adoption, specifically $\$ 1$ per adopted hectare. Thus, if adoption occurs on $10 \%$ of the rice and wheat area $\left(8.3 \times 10^{6} \mathrm{ha}\right)$, then a fixed undiscounted extension cost of $\$ 8.3 \times 10^{6}$ is incurred. Varieties are assumed to come on line gradually after year 10 of the simulation, e.g. in a $10 \%$ adoption scenario, to cover $2 \%$ of total area in year $11,4 \%$ in year $12,6 \%$ in year $13,8 \%$ in year 14 , and $10 \%$ of the total area in all years thereafter. Recurrent costs (such as for maintenance breeding) of $\$ 250000$ annually are assumed after the initial 10-year period of fixed investments. Thus, in a 25 -year simulation, assuming a $10 \%$ adoption rate, $\$ 42 \times 10^{6}$ in undiscounted costs may be incurred in total.

Nutritional benefits are tied to assumed rates in reduction of anaemia. Using an analysis by Bhargava et al. (2001), which provided empirical estimates of the relationship between haemoglobin levels of rural Bangladeshi women and their intakes of $\mathrm{Fe}$ and other nutrients and compounds, it is conservatively estimated that anaemia prevalence rates would be reduced by $3 \%$ in those who consume the nutritious rice and wheat (e.g. a reduction of $3 \%$ of $10 \%$ of the population under a $10 \%$ adoption scenario, or 3.375 million cases of anaemia averted each year). Benefits to cases of anaemia averted are those estimated by Horton \& Ross (1999) for India and Bangladesh, a discounted present lifetime value of $\$ 27.50$ per case.

Even these conservative assumptions of nutrition benefits well justify the investment cost (as shown in Table 3). In addition, however, as discussed, for example, in Graham et al. (2001) increased seed $\mathrm{Zn}$ density may increase rice and wheat yields substantially and lower seeding rates. Yield increases of $250 \mathrm{~kg}$ ( $8 \%$ on a base yield of 3 tonne/ha) of unmilled rice and wheat are assumed on adopted areas, giving a net incremental undiscounted profit of about $\$ 35 /$ ha per year.

Even though all centralised fixed costs of $\$ 25 \times 10^{6}$ are charged to India and Bangladesh, Table 3 suggests that nutritious varieties may reach undernourished populations at a cost of just 2-3 cents per person per year. Depending on adoption rates and the levels of $\mathrm{Fe}$ that can be added to food staples through breeding, anaemia may be averted for as low as $22-36$ cents per case. Internal rates of return on nutrition benefits should be $>25 \%$. If agricultural benefits are also considered, several billions of dollars of benefits can be expected on investments of tens of millions of dollars.

\section{Conclusions}

The time is long overdue for involving agricultural research directly in the fight against micronutrient malnutrition. As trace minerals are important not only for human nutrition, but also for plant nutrition, plant breeding holds great promise for making a major, low-cost and sustainable contribution to reducing micronutrient, particularly mineral, deficiencies in man, and may have important spin-off effects for increasing farm productivity in developing countries in a way that is environmentally beneficial.

Results so far obtained under the Consultative Group on International Agricultural Research Micronutrient Project (Graham et al. 1999) indicate that the breeding parameters are not difficult and are highly likely to be low cost. The following points are seminal: 
Table 3. Simulated benefits and costs over 25 years of developing iron- and zinc-dense rice varieties for India and Bangladesh

\begin{tabular}{|c|c|c|c|c|c|c|}
\hline \multirow[b]{4}{*}{ Description of benefits and costs } & \multicolumn{6}{|c|}{ Variety adoption rate (\%) } \\
\hline & \multicolumn{3}{|c|}{10} & \multicolumn{3}{|c|}{20} \\
\hline & \multicolumn{3}{|c|}{ Anaemia reduction rate $(\%)$} & \multicolumn{3}{|c|}{ Anaemia reduction rate $(\%)$} \\
\hline & 3 & 4 & 8 & 3 & 4 & 8 \\
\hline $\begin{array}{l}\text { Cost per person reached who consumes nutritious } \\
\text { staples (undiscounted) }\end{array}$ & 0.03 & 0.03 & 0.03 & $0 \cdot 02$ & $0 \cdot 02$ & 0.02 \\
\hline Cost per case of anaemia avoided (undiscounted) & 0.96 & $0 \cdot 72$ & 0.36 & 0.58 & 0.44 & $0 \cdot 22$ \\
\hline Internal rate of return on nutrition benefit (\%) & $28 \cdot 9$ & $31 \cdot 8$ & $39 \cdot 2$ & $34 \cdot 0$ & $37 \cdot 1$ & $44 \cdot 9$ \\
\hline $\begin{array}{l}\text { Total investment for research and extension } \\
\left(\$ \times 10^{6} ; \text { undiscounted }\right)\end{array}$ & $42 \cdot 1$ & $42 \cdot 1$ & $42 \cdot 1$ & $51 \cdot 2$ & $51 \cdot 2$ & $51 \cdot 2$ \\
\hline Total nutrition benefits ( $3 \%$ discount rate; $\$ \times 10^{6}$ ) & $694 \cdot 2$ & $925 \cdot 6$ & $1851 \cdot 2$ & $1388 \cdot 4$ & $1851 \cdot 2$ & $3702 \cdot 4$ \\
\hline Total agricultural benefits ( $3 \%$ discount rate; $\$ \times 10^{6}$ ) & $2142 \cdot 7$ & $2142 \cdot 7$ & $2142 \cdot 7$ & $4285 \cdot 3$ & $4285 \cdot 3$ & $4285 \cdot 3$ \\
\hline Total benefits ( $3 \%$ discount rate; $\$ \times 10^{6}$ ) & $2836 \cdot 9$ & $3068 \cdot 3$ & 3933.9 & $5673 \cdot 7$ & $6136 \cdot 5$ & $7987 \cdot 7$ \\
\hline Total Costs ( $3 \%$ discount rate; $\$ \times 10^{6}$ ) & 35.9 & 35.9 & 35.9 & $43 \cdot 7$ & $43 \cdot 7$ & $43 \cdot 7$ \\
\hline Nutrition benefits:total costs & $19 \cdot 3$ & $25 \cdot 8$ & $51 \cdot 5$ & $31 \cdot 8$ & $42 \cdot 4$ & $84 \cdot 7$ \\
\hline
\end{tabular}

1 adequate genetic variation in concentrations of $\beta$-carotene, other functional carotenoids, Fe, $\mathrm{Zn}$ and other minerals exists in the major germplasm banks to justify selection;

2. micronutrient-density traits are stable across environments;

3. in all crops studied it is possible to combine the high micronutrient-density trait with high yield, unlike protein content and yield, which are negatively correlated;

4. genetic control is simple enough to make breeding economic;

5. it will be possible to improve the content of several limiting micronutrients together, thus pushing populations towards nutritional balance;

6. bioavailability of the extra nutrient in elite breeding lines is high for rats and, where the density is high enough for the test, also to human colon cell lines. Tests on human subjects are now a high priority.

Thus, some successes in increasing the mineral content of staples can be achieved in the short term through conventional breeding techniques, because of the inherent compatibility of high yields and trace mineral density in the seeds. After feasibility and practicality are established for specific crops and nutrients using conventional breeding, the hope is that transgenic techniques can then be applied to improve the nutritional content of food staples by: (1) perhaps increasing mineral levels even further than is possible with conventional breeding techniques; (2) pursuing complementary strategies, such as adding $\beta$-carotene and heat-stable phytase genes in rice, which are not possible using conventional breeding techniques (for a discussion of the application of biotechnology, see Bouis, 2000; also, see Beyer et al. 2002; Holm et al. 2002).

The final permanent solution to micronutrient malnutrition in developing countries is a substantial improvement in dietary quality, i.e. higher consumption of pulses, fruits, vegetables, fish and animal products, which the poor already desire but cannot presently afford. Achieving this objective will require several decades and involve billions of dollars of investments in infrastructure and research to increase the production of non-staple foods. Meanwhile, breeding staple foods that are dense in minerals and vitamins provides a low-cost sustainable strategy for helping to reduce levels of micronutrient malnutrition. Biofortification complements conventional interventions.

The two key issues on which success will turn are:

(1) will staple varieties with mineral-dense seeds be widely adopted by farmers in developing countries, either because of agronomic advantages on trace mineraldeficient soils or through this characteristic being bred into the highest-yielding varieties;

(2) will the additional nutrients contained in the seeds be of sufficient magnitude and bioavailability that they will have an appreciable impact on micronutrient status?

\section{References}

ACC/SCN (2000) Fourth Report on the World Nutrition Situation. Geneva: ACC/SCN/International Food Policy Research Institute.

Beaton GH, Martorell R, Aronson KJ, Edmonston B, McCabe G, Ross AC \& Harvey B (1993) Effectiveness of Vitamin A Supplementation in the Control of Young Child Morbidity and Mortality in Developing Countries. ACC/SCN State-of-the-Art Series, Nutrition Policy Discussion Paper no. 13. Geneva: $\mathrm{ACC} / \mathrm{SCN}$

Beyer P, Al-Babili S, Ye X, Lucca P, Schaub P, Welsch R \& Potrykus I (2002) Golden rice: Introducing the B-carotene biosynthesis pathway into rice endosperm by genetic engineering to defeat vitamin A deficiency. Journal of Nutrition 132, 506-510.

Bhargava A, Bouis H \& Schrimshaw N (2001) Dietary intakes and socioeconomic factors are associated with the hemoglobin concentration of Bangladeshi women. Journal of Nutrition 131, 758-764.

Bhutta ZA, Bird SM, Black RE, Brown KH, Gardner JM, Hidayat A, Khatun F, Martorell R, Ninh NX, Penny ME, Rosado JL, Roy SK, Ruel M, Sazawal S \& Shankar A (2000) Therapeutic effects of oral zinc in acute and persistent diarrhoea in children in developing countries: Pooled analysis of randomized controlled trial. Zinc Investigators' Collaborative Group. American Journal of Clinical Nutrition 72, 1516-1522.

Bhutta ZA, Black RE, Brown KH, Gardner JM, Gore S, Hidayat A, Khatun F, Martorell R, Ninh NX, Penny ME, Rosado JL, Roy 
SK, Ruel M, Sazawal S \& Shankar A (1999) Prevention of diarrhea and pneumonia by zinc supplementation in children in developing countries: Pooled analysis of randomized controlled trials. Zinc Investigators' Collaborative Group. Journal of Pediatrics 135, 689-697.

Black RE (1998) Therapeutic and preventive effects of zinc on serious childhood infectious diseases in developing countries. American Journal of Clinical Nutrition 68, S476-S479.

Bouis HE (2000) The role of biotechnology for food consumers in developing countries. In Agricultural Biotechnology in Developing Countries: Towards Optimizing Benefits for the Poor, pp. 189-213 [M Qaim, M Krattiger and J von Braun, editors]. Boston, MA: Kluwer Academic Publishers.

Bouis $\mathrm{H}$, de la Brière $\mathrm{B}$, Guitierrez L, Hallman K, Hassan N, Hels O, Quabili W, Quisumbing A, Thilsted S, Zihad Z \& Zohir S (1998) Commercial Vegetable and Polyculture Fish Production in Bangladesh: Impacts on Income, Household Resource Allocation, and Nutrition. Washington, DC: International Food Policy Research Institute.

Bouis HE \& Haddad LJ (1990) Agricultural Commercialization, Nutrition, and the Rural Poor: A Study of Philippine Farm Households. Boulder, CO: Lynne Rienner Publishers.

Bouis HE \& Novenario-Reese MJ (1997) The Determinants of Demand for Micronutrients: An Analysis of Rural Households in Bangladesh. Food Consumption and Nutrition Division Discussion Paper no. 32. Washington, DC: International Food Policy Research Institute.

Brown KH \& Wuehler SE (editors) (2000) Zinc and Human Health: Results of Recent Trials and Implications for Programme Interventions and Research. Ottawa, Canada: The Micronutrient Initiative/International Development Research Centre.

Food and Agriculture Organization (1999) FAOSTAT Agriculture Data. http://apps.fao.org/page/collections? subset=agriculture

Glahn RP, Cheng Z, Welch RM \& Gregorio GB (2002) Comparison of iron bioavailability from 15 rice genotypes: Studies using an in vitro digestion/Caco-2 culture model. Journal of Agricultural and Food Chemistry 50, 3586-3591.

Graham RD (1978) Nutrient efficiency objectives in cereal breeding. Proceedings of the 8th International Colloquium on Plant Analysis and Fertilizer Problems. New Zealand Division of Scientific and Industrial Research Information Series no. 134, pp. 165-170 [AR Fergusen, RL Bieleski and IB Ferguson, editors]. Wellington, New Zealand: Government Printer.

Graham RD (1991) Breeding wheats for tolerance to micronutrient deficient soil: Present status and priorities. In Wheat for the Nontraditional Warm Areas [DA Saunders, editor]. Mexico City, Mexico: Centro Internacional de Mejoramiento de Maiz y Trigo.

Graham RD \& Rovira AD (1984) A role for manganese in the resistance of what to take-all. Plant and Soil 78, 441-444.

Graham RD, Senadhira D, Beebe SE, Iglesias C \& Ortiz-Monasterio I (1999) Breeding for micronutrient density in edible portions of staple food crops: Conventional approaches. Field Crops Research 60, 57-80.

Graham RD \& Welch RM (1996) Breeding for Staple Food Crops with High Micronutrient Density. Agricultural Strategies for Micronutrients Working Paper 3. Washington, DC: International Food Policy Research Institute.

Graham R, Welch R \& Bouis H (2001) Addressing micronutrient malnutrition through the nutritional quality of staple foods: Principles, perspectives, and knowledge gaps. Advances in Agronomy 70, 77-142.

Hallberg L (1981) Bioavailability of dietary iron in man. Annual Review of Nutrition 1, 123-127.

Holm P, Kristiansen KN \& Pedersen HB (2002) Transgenic approaches in commonly consumed cereals to improve iron and zinc content and bioavailability. Journal of Nutrition 132, 514-516.

Horton S \& Ross J (1999) Economic Consequences of Iron Deficiency. Forthcoming Technical Paper. Ottawa, Canada: The Micronutrient Initiative.

Marschner H (1995) Mineral Nutrition of Higher Plants, 2nd ed. London: Academic Press.

Perry GS, Yip R \& Zyrkowski C (1995) Nutritional risk factors among low-income pregnant US women: The Centers for Disease Control and Prevention (CDC) Pregnant Nutrition Surveillance System, 1979-1993. Seminars in Perinatology 19, 211-221.

Raboy V (2002) Progress in breeding low phytate crops. Journal of Nutrition 132, 503-505.

Rengel Z \& Graham RD (1995a) Importance of seed Zn content for wheat growth on $\mathrm{Zn}$-deficient soil: I. Vegetative growth. Plant and Soil 173, 259-266.

Rengel Z \& Graham RD (1995b) Importance of seed Zn content for wheat growth on $\mathrm{Zn}$-deficient soil: II. Grain yield. Plant and Soil 173, 267-274.

Roy SK, Tomkins AM, Haider R, Behren RH, Akramuzzaman SM, Mahalanabis D \& Fuchs CJ (1999) Impact of zinc supplementation on subsequent growth and morbidity in Bangladeshi children with acute diarrhoea. European Journal of Clinical Nutrition 53, 529-534.

Shankar AH, Genton B, Baisor M, Paino J, Tamja S, Adiguma T, Wu L, Rare L, Bannon D, Tielsch JM, West KP Jr \& Alpers MP (2000) The influence of zinc supplementation on morbidity due to Plasmodium malaria: A randomised trial in preschool children in Papua New Guinea. American Journal of Tropical Medicine and Hygiene 62, 663-669.

Shankar AH, Genton B, Semba RD, Baisor M, Paino J, Tamja S, Adiguma T, Wu L, Rare L, Tielsch JM, Alpers MP \& West KP $\mathrm{Jr}$ (1999) Effect of vitamin A supplementation on morbidity due to Plasmodium falciparum in young children in Papua New Guinea: A randomised trial. Lancet 354, 203-209.

Sillanpää M (1990) Micronutrient assessment at the country level: an international study. FAO Soils Bulletin 48. Rome: FAO.

Sommer A \& West KP (editors) (1996) Vitamin A Deficiency: Health, Survival, and Vision. New York: Oxford University Press.

Sparrow DH \& Graham RD (1988) Susceptibility of zinc-deficient wheat plants to colonization by Fusarium graminearum Schw. Group 1. Plant and Soil 112, 261-266.

Stoltzfus RJ (2001) Defining iron-deficiency anemia in public health terms: A time for reflection. Journal of Nutrition 131, 565S-567S.

Thongbai P, Hannam RJ, Graham RD \& Webb MJ (1993) Zinc nutrition and rhizoctoria root rot of cereals. Plant and Soil 153, 207-214.

Umeta M, West CE, Haidar J, Deurenberg P \& Hautvast JG (2000) Zinc supplementation and stunted infants in Ethiopia: A randomised controlled trial. Lancet 355, 2021-2026.

Villamor E \& Fawzi WW (2000) Vitamin A supplementation: Implications for morbidity and mortality in children. Journal of Infectious Diseases 182, Suppl. 1, S122-S133.

Welch RM (1986) Effects of nutrient deficiencies on seed production and quality. Advances in Plant Nutrition 2, 205-247.

Welch RM (1993) Zinc concentrations and forms in plants for humans and animals. In Zinc in Soils and Plants, pp. 183-195 [AD Robson, editor]. Boston, MA: Kluwer Academic Publishers.

Welch RM (1995) Micronutrient nutrition of plants. Critical Reviews in Plant Sciences 14, 49-82.

Welch RM (1999) Importance of seed mineral nutrient reserves in crop growth and development. In Mineral Nutrition of Crops: 
Fundamental Mechanisms and Implications, pp. 205-226 [Z Rengel, editor]. New York: Food Products Press.

Welch RM, House WA, Beebe S \& Cheng Z (2000) Genetic selection for enhanced bioavailable levels of iron in bean (Phaseolus vulgaris L.) seeds. Journal of Agricultural and Food Chemistry 48, 3576-3580.

West CE (2000) Vitamin A and measles. Nutrition Reviews 58, S46-S54.

Wise A (1995) Phytate and zinc bioavailability. International Journal of Food Sciences and Nutrition 46, 53-63.
World Bank (1994) Enriching Lives: Overcoming Vitamin and Mineral Malnutrition in Developing Countries. Development in Practice Series. Washington, DC: World Bank.

Yang X \& Römheld V (1999) Physiological and genetic aspects of micronutrient uptake by higher plants. In Plant Nutrition - Molecular Biology and Genetics. Proceedings of the Sixth International Symposium on Genetics and Molecular Biology of Plant Nutrition pp. 151-186 [G Gissel-Nielsen and A Jensen, editors]. Dordrecht, The Netherlands: Kluwer Academic Publishers. 